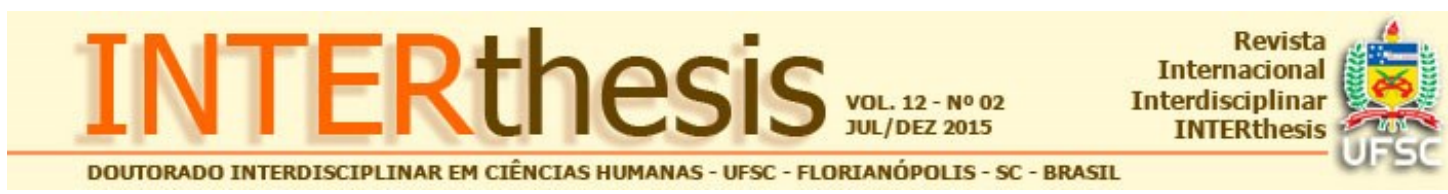

\title{
DINÂMICAS IDENTITÁRIAS NO RURAL-URBANO-RURAL: TERRITÓRIO E FRONTEIRA ENTRE AGRICULTORES DO RIO DE JANEIRO
}

\section{Resumo:}

Cecilia Moreyra Figueiredo ${ }^{1}$ Maria Inácia D’Ávila Neto ${ }^{2}$

O município do Rio de Janeiro é considerado eminentemente urbano, posto que esta é a condição de $100 \%$ de sua população. No entanto, a realidade que observamos transpassa os dados censitários oficiais, e a agricultura de caráter familiar permanece ativa em algumas comunidades. Este estudo se realiza no campo psicossociológico a partir de uma perspectiva interdisciplinar e analisa as dinâmicas identitárias entre agricultores da cidade do Rio de Janeiro a partir das noções de fronteira e identidade próprias da teoria pós-colonial. Focalizamos uma comunidade que apresenta histórias centenárias de práticas ligadas à agricultura, que evidenciam forte consciência coletiva sobre seu papel social: afirmam sua permanência no lugar como fator de preservação da floresta da região e atribuem ao seu trabalho a devida importância em suas relações sociais. Neste sentido abordaremos o tema a partir das perspectivas teóricas da sociologia das ausências e da ecologia de saberes, conforme nos apresenta Boaventura de Sousa Santos.

Palavras-chave: Interdisciplinaridade. Comunidades. Identidades. Fronteira. Póscolonialismo.

\section{INTRODUÇÃO}

Este artigo busca investigar as dinâmicas identitárias entre agricultores no território rural-urbano-rural, a partir de uma comunidade de agricultores familiares da cidade do Rio de Janeiro, onde estes atores, bem como a própria prática da agricultura estão invisibilizados. A pesquisa, realizada em nível de doutorado no âmbito do programa EICOS, Psicossociologia de Comunidade e Ecologia Social, que tem como objetivo cartografar as identidades de agricultores em dois municípios da região metropolitana do Rio Janeiro buscando, através de imagens fotográficas,

\footnotetext{
1 Doutoranda em Psicossociologia pelo Programa de Pós-Graduação em Psicossociologia de Comunidades e Ecologia Social - Programa EICOS da Universidade Federal do Rio de Janeiro pesquisadora no Laboratório de Imagens: gênero, corpo, espaço, participação e desenvolvimento no mesmo Programa. Pesquisadora dos grupos de pesquisa Núcleo Ambiente, território e identidade da Universidade Federal Rural do Rio de Janeiro, Rio de Janeiro, RJ. E-mail: cissafig@gmail.com

2 Doutorado em Psicologia Social pela Université Paris Diderot, Paris 7, França. Professora Titular da Universidade Federal do Rio de Janeiro, coordenando uma UNESCO chair on sustainable development sediada no Programa de Pós-Graduação em Psicossociologia de Comunidades e Ecologia Social - Programa EICOS, Rio de Janeiro, RJ. E-mail: davila@gmail.com
}

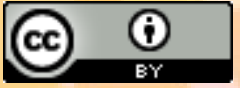

Esta obra foi licenciada com uma Licença Creative Commons - Atribuição 3.0 Não Adaptada. 
captar os sentidos e os sentimentos destes atores sociais em relação ao trabalho na agricultura e suas identidades psicossociais em contexto de forte urbanização. Os depoimentos que servem de base para as reflexões apresentadas neste artigo foram retirados de um documentário realizado pela pesquisadora em 2012 e que serviu como ponto de partida para o desenvolvimento do projeto de pesquisa. Os participantes deste documentário assinaram um termo de uso de imagem e voz e optaram por utilizar seus nomes verdadeiros.

Partirmos da crítica realizada por Monteiro, Ericeira, Froelich e Silva (2013), sobre os estudos realizados nas cidades, que ao enfatizarem os aspectos macrossociológicos desagregadores dos espaços urbanos (deficiência da rede de transportes, falta de moradia, saneamento básico precário, etc), não promovem a visibilidade dos atores sociais que circulam nas e pelas cidades.

O município do Rio de Janeiro é um exemplo claro desta visão. Com uma taxa oficial de $100 \%$ de urbanização, ou seja, tendo seus mais de 6 milhões de habitantes residindo em áreas urbanas, a cidade está planejada política, administrativa e economicamente a partir desta visão de urbanidade. Os dados numéricos muitas vezes encobrem a visão mais profunda de uma realidade sociocultural, que é produzida no cotidiano vivido pelos que se auto designam agricultores, vivem segundo este autoconceito e adotam a atividade agrícola como modo de existência. São estes grupos que hoje mantém viva a agricultura familiar na cidade e representam um importante setor populacional, que tem na agricultura uma de suas estratégias de reprodução social. Aqui observamos um fenômeno que se estabelece fora da lógica hegemônica de urbanização que caracteriza a cidade do Rio de Janeiro. Configura-se aqui uma situação psicossocial onde a agricultura familiar se destaca tanto como um modo de existência quanto como uma atividade econômica.

Na primeira parte do artigo, produzimos uma revisão de referenciais teóricos que fundamentam a discussão sobre a dinâmica rural-urbano-rural dos espaços humanos nas cidades como um processo de modernização que se dá, em grade medida, por um fluxo informacional que se encontra em meio caminho entre o rural e o urbano (MARTÍN-BARBERO, 2002). Optamos aqui por caracterizar esta fronteira como rural-urbano-rural, como uma crítica a simplificação apresentada por uma dicotomia de separação rural-urbano. Entendemos assim, que entre rural e urbano 
existem continuidades e permeabilidades, desta forma optamos por olhar para este território através de uma cartografia de relações, buscando um entrelaçamento das identidades a partir da experiência e da narrativa dos agricultores com o objetivo de superar as fissuras e buscar os "fluxos nos quais se gestam outras ordens" (MARTíN-BARBERO, 2002, p. 277).

No segundo momento, analisamos depoimentos de agricultores urbanos, recolhidos do documentário "Agricultura Mora em Mim: A face invisível da cidade". A seleção dos mesmos tem a finalidade de discutir as dinâmicas das identidades psicossociais em um contexto onde rural e urbano se misturam, criando fronteiras fluidas dentro da cidade do Rio de Janeiro. Os depoimentos selecionados foram gravados na comunidade Astrogilda, localizada no Maciço da Pedra Branca, bairro da Vargem Grande. Esta é uma das muitas comunidades de agricultores que residem em um local, onde desde 1974 foi criado o Parque Estadual da Pedra Branca, considerada a maior reserva florestal em área urbana no mundo, com 12.393 Hectares, que abrangem 17 bairros na Zona Oeste da cidade do Rio de Janeiro $^{3}$. Os depoimentos de três moradores locais ajudarão a compreender o contexto no qual se gesta esta dinâmica identitária, bem como a sua inserção no debate do pós-colonialismo.

Como suporte teórico utilizaremos as noções de fronteira e identidade a partir de uma leitura pós-colonial, bem como as elaborações de sobre sociologia das ausências e das emergências, as noções de globalização hegemônica e contrahegemônica (SANTOS, 2010).

\section{RELFEXÕES TEÓRICO-MEDOLÓGICAS SOBRE A RELAÇÃo RURAL- URBANO-RURAL NA GRANDE METRÓPOLE}

A separação rural/urbano surge como questão no pensamento social do século XIX a partir das dicotomias próprias da modernidade. O pensamento político e as práticas sociais ocidentais foram dominados, desde a revolução industrial inglesa até o final do século $X X$, pela ideia de urbanização, entendida como a concentração de recursos técnico/tecnológicos gerados e geridos segundo a

3 Guia de Trilhas Parque Estadual da Pedra Branca. Org. André Ilha, Patrícia Figueiredo de Castro, Alexandre Marau Pedroso, Aline Schneider. Rio de Janeiro. INEA, 2013.

R. Inter. Interdisc. INTERthesis, Florianópolis, v.12, n.2, p.180-199, Jul-Dez. 2015 
expansão da racionalidade tecnocientífica. O espaço urbano aparece, na modernidade, como o espaço de todas as construções humanas que seguem a marcha das conquistas civilizatórias. Segundo Monteiro, Ericeira, Froelich e Silva (2013) ser urbano é não somente pertencer à cidade, mas também ser cortês, afável, civilizado. Certos referenciais analíticos apontam as cidades modernas como uma expressão do capital em expansão, contrastando com as cidades antigas, que sustentavam a relação dialética com o campo. Para Lefebvre (1999), as grandes cidades industriais, comerciais e políticas protagonizam o cenário de passagem para o modo de produção capitalista, no arco econômico e social. Já para Williams (1973) a diferenciação entre campo e cidade do sec. XIX expõe e traduz também uma questão de classe social. O lugar da cidade, apesar de fascinante por sua diversidade era o espaço onde ricos e pobres circulavam juntos, ao passo que nos campos os ricos estavam separados espacialmente e socialmente dos pobres, o que associava a este espaço a ideia de beleza romântica e de autenticidade. Enquanto a cidade era o espaço da modernidade o campo representava a tradição. Esta visão de fragmentação campo/cidade se constituiu como uma construção social de separação de dois mundos distintos constituídos por hierarquias de valores.

Silva e Rocha (2011) relacionam os conceitos de rural e urbano ao longo de uma trajetória de pensamento que remonta às primeiras definições de comunidade onde a dicotomia entre rural e urbano era amplamente difundida. A organização comunitária rural se distinguia da organização social urbana como uma realidade específica e era reconhecida por suas características de coesão emocional e social, pela continuidade e conservadorismo, ao passo que a sociedade urbana estaria marcada por um individualismo, racionalismo e pelo apreço a modernidade. A passagem para o século XX marca, segundo Martins (2000), o pensamento sociológico para o mundo rural visto a partir do urbano e de sua relação com este território. A sociologia rural não era mais que uma sociologia da ocupação agrícola onde o rural era pensado como uma incongruência e relação às fantasias da modernidade. Martins também destaca no pensamento da sociologia rural uma ênfase em olhar as comunidades rurais como caracterizadas por uma homogeneidade e particularizadas por uma similaridade de características psicossociais adquiridas como crenças, opiniões e tradições (MARTINS, 2000). Por 
outro lado, a cidade se configurava como um lócus de coexistências de personalidades heterogêneas e diversas. Estas linhas de pensamento destacadas por Martins e Silva e Rocha marcam a separação rural/urbano em termos de lógicas sociais completamente diferentes entre si.

Os grandes fluxos migratórios entre territórios rurais e urbanos, que marcaram a segunda metade do Século XX, alteraram significativamente este campo de pensamento que passou a refletir sobre um continuum rural-urbano, para além da separação entre estes espaços. Este deslocamento de pessoas de espaços rurais para as cidades produz a coexistência de visões de mundo diferentes (MARTINS, 2000). O modo de ser e a visão de mundo criticas ao desenvolvimento capitalista, a modernização anômala e a desumanização das pessoas surgem como uma força de pensamento dentro dos meios urbanos a partir deste forte contato com culturas rurais. Deslocamentos populacionais mostraram que o rural pode subsistir culturalmente por longos períodos de tempo fora da lógica da prática econômica da agricultura, pois permanece como visão de mundo, como uma nostalgia criativa, estratégias de vida, prática cultural e como identidade. Segundo Silva e Rocha (2011) atualmente o debate sobre as relações rural-urbano se encontra revestido de novas complexidades que apontam para a superação da concepção do rural como espaço agrícola ou como uma área residual, bem como uma superação do urbano como o centro administrativo modernizante.

Martín-Barbero (2002) propõe pensar a cidade como uma narrativa que abarca suas territorialidades e desterritorialidades, seus medos, os jogos e o caos. Ao propor que o crescimento urbano se concretiza menos pela expansão do espaço asfaltado e mais em uma experiência temporal urbana, o autor propõe duas chaves para compreender o processo de modernização das cidades. A primeira delas é o fluxo de migrações, no que chama de descentralização do sagrado que remete diretamente à ideia de movimento constante, tanto de pessoas como de visões de mundo. A cidade fica aqui configurada como um espaço de hibridação. A segunda chave de leitura da cidade proposta pelo autor é a da arte do quebra-cabeça que remete a uma tentativa de observar fissuras que separam as peças, e nos impedem de ver as junções do espaço e de ter noção do todo contribuindo para uma visão estanque da cidade como um sistema fechado. Para Martín-Barbero é preciso 
acompanhar os fluxos discursivos a partir de uma geografia de identidades e superar a percepção fragmentária para perceber a cidade como um todo, não só territorial, mas também no que tange as experiências sociais, culturais e identitárias dos sujeitos que habitam este espaço.

Pelo viés do pensamento nômade e multidimensional Martín-Barbero afirma que "nossas cidades são, hoje, o ambíguo, o enigmático cenário de algo que não é representado nem pela diferença excludente e excluída do autóctone, nem pela inclusão uniformizante e dissolvente do moderno" (MARTíN-BARBERO 2002, p. 279). Este pensamento configura modos de estar e sentir juntos, que desarticula as formas tradicionais de coesão e modifica estruturalmente as formas de socialidade.

A reflexão proposta pelo autor é uma resposta à forma com a qual a cidade do paradigma modernizador é vista e pensada politicamente, espacialmente e socialmente. A realidade das regiões metropolitanas das cidades lationamericanas é a do crescimento voraz a partir de uma urbanidade modernizadora que relaciona diretamente progresso a espaço asfaltado e esquece que as mobilidades espaciais e culturais são parte do mesmo fluxo. As fissuras se acentuam agudizando diferenças e hierarquias de uso e direito ao espaço. A massificação do urbano é parte fundante da modernidade-mundo, que produz o acelerado e ambíguo processo de globalização da economia e da cultura.

A urbanização aqui representa uma ruptura com a sensibilidade e vai além do acesso a bens e equipamentos públicos como asfalto, água, luz, saúde, e se reflete no desenraizamento, no crescimento da marginalização, a na separação entre trabalho e vida e perda de memórias sociais. Mas como poderíamos, a partir destas reflexões de Martín-Barbero, explicar a permanência da agricultura e de agricultores em territórios onde a expansão do urbano é um fenômeno latente e aparentemente tão impiedoso?

Para nos aproximarmos desta resposta nos apoiamos na diferenciação que Santos (2010) faz entre globalização hegemônica e globalização contrahegemônica, em que a primeira é um "processo através do qual um dado fenômeno ou entidade local consegue difundir-se globalmente e, ao fazê-lo, adquire a capacidade de designar um fenômeno ou uma entidade rival como local" (SANTOS, 2010: 195). Segundo o autor o discurso hegemônico é uma narrativa da história 
embasada pelo discurso científico, que utiliza como recurso de afirmação o desaparecimento de culturas locais. No entanto, Santos insiste em afirmar que frente ao processo de globalização hegemônica surge uma profusão de novos paradigmas emancipatórios, plurais e interculturais que privilegiam uma ecologia de saberes.

Observamos aqui que os atores apontam para a necessidade de refletir sobre a urbanidade como um processo narrativo, fruto de fluxos e hibridações culturais. No entanto há uma outra narrativa onde o urbano representa uma massificação de culturas e identidades, sustentada no fracionamento e na separação das peças do quebra-cabeça que formam o espaço da cidade. Estas mesmas peças separam a cultura hegemônica, das culturas contra-hegemônicas e separam o urbano e o rural, produzindo hierarquizações de sentidos para estas duas representações. Relacionando as reflexões propostas pelos dois autores podemos entender melhor a permanência, em forma de resistência, da agricultura como atividade econômica e prática cultural no município do Rio de Janeiro pelo viés da contra-hegemonia.

Os poderes hegemônicos que comandam a globalização neoliberal, a sociedade de consumo e da informação, têm vindo a promover teorias e imagens que apelam a uma totalidade. No entanto esta é uma totalidade que reduz a realidade e ao que Martin-Barbero chama de tempo homogêneo e monótono da modernidade fazendo com que a cidade seja traçada por rotas previsíveis, vinculadas aos tráfegos rotineiros entre um centro e as suas periferias por caminhos que possuem usos puramente funcionais. Como uma solução para esta monotonia urbana o autor propõe o descentramentos e a desurbanização das cidades, ou seja, a perda dos centros convencionais e sua substituição por uma configuração de cidade a partir de circuitos conectados em rede cuja topologia supõe a equivalência de todos os lugares e o reconhecimento da existência de uma cultura rural dentro do urbano seja por fluxos migratórios ou por remanescências.

Neste sentido é possível aproximar estas reflexões, como metáforas, para pensar as fronteiras entre rural e urbano, assim como a permanência da agricultura na região metropolitana do Rio de Janeiro, como formas que se interpenetram adquirindo uma dinâmica própria. O gradiente que compõem o rural-urbano-rural constitui uma imagem forte para pensar a cidade do Rio de Janeiro atualmente e nos coloca algumas questões:

R. Inter. Interdisc. INTERthesis, Florianópolis, v.12, n.2, p.180-199, Jul-Dez. 2015 
Qual o grau de visibilidade/invisibilidade dos agricultores e da agricultura neste modelo de desenvolvimento urbano? Como este grupo enxerga seu modo de existência? Quais são as implicações identitárias para este grupo inserido neste modelo de urbanidade?

\section{O PROBLEMA DA INVISIBILIDADE E A PRODUÇÃO DA NÃO EXISTÊNCIA A PARTIR DE DEPOIMENTOS DOS AGRICULTORES}

Para chegar à comunidade Astrogilda é necessário subir o caminho do Cafundá adentrando o Maciço da Pedra Branca onde há mais de cinco gerações sobem e descem agricultores, em sua maioria negros, carregando nos lombos dos burros a sua produção de banana, mamão, aipim, caqui, agrião e taioba. Segundo Sandro, morador do local, a comunidade foi constituída por escravos de uma antiga fazenda, que permaneceram na região e se mantém até hoje como uma comunidade agrícola ${ }^{4}$.

No caminho de terra que leva até a comunidade Astrogilda as casas vão se escasseando, e a estrada se torna cada vez mais declivosa e estreita. A cada curva percebemos em sons e imagens, cheiros e cores, que nos distanciamos da cidade, do barulho dos carros, do movimento frenético. Os carros já não sobem mais, somente algumas motos circulam. Logo podemos ver a placa que delimita a comunidade, que é nosso destino final.

Astrogilda é, nas palavras de Sandro, morador o local, "a matriarca da comunidade e de todos que moram aqui" 5 . Segundo ele, esta senhora teve um papel muito importante na manutenção da unidade das famílias que ali permaneceram: "Todos nós somos seus descendentes, somos todos parentes e vivemos aqui nesta comunidade como agricultores".

Sandro desponta como uma liderança política, que defende com firmeza a importância da sua comunidade para o território do Maciço tanto em termos culturais quanto ecológicos. Segundo ele a prática da agricultura é o principal fator de

\footnotetext{
${ }^{4}$ Em 16 de agosto de 2014 a comunidade Astrogilda recebeu o certificado de remanescente de quilombo pela Fundação Palmares.

${ }_{5}^{5}$ Optamos por destacar as falas originais dos interlocutores entre aspas e em itálico, mesmo quando as mesmas seguem no corpo do texto.
}

R. Inter. Interdisc. INTERthesis, Florianópolis, v.12, n.2, p.180-199, Jul-Dez. 2015 
preservação da floresta da região, pois os agricultores plantam e constroem suas casas sem desmatar ou causar grandes impactos na floresta: "Se as nossas comunidades não existissem aqui a "especulação imobiliária" já teria loteado e construído grandes casas destruindo a floresta".

A fala de Sandro é o reflexo de um conflito, algumas vezes velado, em outros mais explicito, entre as comunidades de agricultores residentes na área do Parque Estadual da Pedra Branca com o órgão ambiental local e com o Poder Público que o gerencia. A presença de agricultores não é permitida em áreas de preservação integral, mas estas comunidades já residiam neste território antes mesmo da delimitação do parque. As comunidades nunca foram expulsas, mas, por não terem titulação da terra, vivem sob constante ameaça de remoção e se mantém na invisibilidade.

Ao apresentar o conflito vivido por sua comunidade, Sandro expõe um componente importante da realidade da agricultura presente no Rio de Janeiro e nos municípios da região metropolitana, a invisibilização das práticas agrícolas, bem como de muitos signos de ruralidade ainda presentes nas áreas urbanas. Esta invisibilidade da agricultura não significa seu desaparecimento, mas sim a consolidação de uma fronteira permeável e descontínua entre o rural e o urbano dentro da própria cidade. O problema da invisibilidade foi abordado por Santos (2010) como fruto da produção social de uma não-existência. Esta produção de não existência aparece com clareza na fala do agricultor Jorge: "Devido à gente não ser reconhecido a gente se acha diferente. Não diferente das outras pessoas, mas parece que a gente não existe".

Esta invisibilização ou não existência da agricultura familiar na cidade do Rio de Janeiro acarreta profundos impactos na dinâmica identitária destes agricultores conforme nos aponta Francisco: "Foi se perdendo esta identidade. O agricultor do Maciço já não quer mais ser visto como agricultor. A gente está falando e uma atividade que não é reconhecida no município (Rio de Janeiro). Oficialmente não temos agricultura no município".

Francisco se refere em sua fala dos dados oficiais do Censo demográfico de 2010 do IBGE que indicam que não há área rural no município do Rio de Janeiro, sendo este $100 \%$ urbano. Estas formulações político-administrativas têm 
representado uma grande dificuldade para estes agricultores no que tange ao acesso a políticas públicas de comercialização de seus produtos.

A partir das colocações de nossos interlocutores nos parece proveitoso apresentar as proposições de Santos (2006) sobre a sociologia das ausências e analisar o que o autor chamou de cindo modos de produção da não-existência: A monocultura do saber, a monocultura do tempo linear, a lógica da classificação social, a lógica da escala dominante e a lógica do produtivismo capitalista. Frente a estas cinco dimensões de exclusão e marginalização de determinado fenômeno social se encontra a proposta de uma abordagem por uma ecologia de saberes.

A monocultura do saber é, o modo mais contundente de produção da nãoexistência, onde a ciência moderna e a alta cultura são os critérios únicos de verdade e qualidade estética. Aqui entendemos que a lógica de urbanização encontra profunda ressonância e sustentação neste sentido monocultural do saber. Uma lógica modernizante que entende que todos os processos sociais estão inseridos e se encontram norteados no sentido de uma modernização urbana. Dentro desta lógica não seria possível conceber a permanência da agricultura em um território urbano. No entanto se a prática permanece viva e ativa, esta se dá a partir de sua invisibilidade. O que podemos observar a partir dos depoimentos dos agricultores da comunidade Astrogilda é que a tensão entre a afirmação da existência da agricultura familiar e a sua invisibilização se encontra em um projeto político modernizador de cidade. Por outro lado, a afirmação da existência desta prática se torna uma forma de luta particular que se traduz por uma revisão de paradigmas e a proposição de uma visão nova de cidade que admita a multiplicidade e o fim das dicotomias.

Esta mesma lógica de urbanização também se sustenta no que Santos configurou como a monocultura do tempo linear. Apontando para um sentido único da história a partir da noção de desenvolvimento e progresso a cidade está inserida neste processo histórico, essencializado e imutável de urbanidade, onde os resquícios de ruralidade estão fadados ao desaparecimento, ou como foi apontado anteriormente, como algo residual.

A lógica da classificação social e a naturalização da hierarquia social como processos inquestionáveis faz com que urbanização se torne natural em seu avanço

R. Inter. Interdisc. INTERthesis, Florianópolis, v.12, n.2, p.180-199, Jul-Dez. 2015 
sobre o território rural, segundo os critérios de modernidade e atraso a relação entre rural e urbano. Esta lógica de classificação social se relaciona com nosso imaginário mais usual e corriqueiro.

Do mesmo modo, a lógica da escala dominante prioriza processos globais e universais aos processos locais e particulares, onde estes ficam aprisionados em escalas que os incapacitam enquanto alternativas. A invisiblização não é fruto somente da incapacidade de enxergar determinadas lógicas diversas, mas um mecanismo que produz a exclusão. A lógica estabelecida determina que a agricultura familiar existe no Rio de Janeiro quanto um resíduo de uma atividade econômica anterior, e que está fadada ao desaparecimento. No entanto este pensamento determinista se estabelece a partir da folclorização do olhar sobre a realidade.

A última lógica de produção da não existência proposta por Santos se relaciona ao produtivismo capitalista e está fortemente relacionada às noções de progresso e desenvolvimento econômico global. Neste ponto se faz necessário apresentar algumas abordagens de Ploeg (2009) sobre a dificuldade da sociedade moderna em compreender e perceber o fenômeno de permanência da agricultura familiar nos processos de globalização hegemônicos. Ploeg aponta para um processo de recampesinização como uma forma de resistência da agricultura familiar em uma luta por autonomia na era da globalização.

Ao afirmar que a principal diferença entre a agricultura familiar e a agricultura empresarial se baseia na lógica do emprego de recursos, o autor admite que a agricultura camponesa está baseada no capital ecológico da natureza viva. A lógica camponesa provém de uma relação coesa com o território, com o qual estabelece uma troca não mercantilizada. Outro ponto que difere a agricultura familiar da agricultura empresaria reside em uma condição camponesa dentro de uma luta por autonomia e progresso como forma de construção de um modo de vida rural. Este modo de vida se encontra marginalizado em ambientes hostis que geram privação e insegurança para os agricultores familiares.

Esta luta por autonomia implica a construção, uso e desenvolvimento contínuo do capital ecológico, baseado em recursos não-mercantilizáveis, fruto de uma coprodução do ser humano com a natureza. Isso significa dizer que o ambiente no qual a agricultura está inserida influencia significativamente a condição de 
desenvolvimento do trabalho. Além do ambiente físico, solo, clima e recursos naturais o ambiente político-econômico, também possui grande influência no desenvolvimento da agricultura familiar. Se o espaço político-econômico não estiver disponível, em razão de interações negativas entre agricultura e a sociedade à qual ela pertence, a capacidade de concretizar esses potenciais será bloqueada. $\mathrm{Na}$ mesma medida, o progresso constituído pelo camponês em determinada região reverte-se diretamente em crescimento em nível local e regional.

A proposição de que a agricultura familiar se relaciona com o território, tanto ecológica quando socialmente em um espaço vivo de experiências que sejam socialmente apreensíveis possui fortes relações com a concepção de Santos sobre a ecologia de saberes enquanto uma resposta crítica ao processo de produção social da não existência.

Ploeg destaca a dimensão do trabalho na agricultura além da produção mercantilizada de alimentos e aponta para uma relação baseada em uma lógica de troca com a natureza, ou seja, onde ou recursos naturais sejam ao mesmo tempo meio e fim do processo de trabalho realizado pelo agricultor. O capital ecológico, epistêmico e cultural gerado pela agricultura familiar são as principais condições de enfrentamento aos ambientes políticos e sociais hostis à existência da prática social, econômica e cultural da agricultura e a sua invisibilidade.

A partir do conceito de recampesinização de Ploeg vemos que o mesmo aponta para a superação de dicotomias historicamente constituídas que geram interpretações empobrecedoras do processo sócio-histórico que enquadram a agricultura familiar camponesa em um lugar de atraso frente ao processo de modernização e formação dos grandes complexos indústrias que formam o agronegócio como potência mundial. Além de situar a presença da agricultura familiar no processo histórico, a noção de recampesinização, segundo Petersen (2009) evidencia que o sentido desse processo não é unidirecional, ou como propõe Santos a partir da noção de monocultura do tempo linear, os processos de recampesinização não significam uma volta ao passado onde reside a noção de atraso e tradição. Pelo contrario, indicam caminhos para a superação de uma encruzilhada civilizacional na qual se insere a sociedade atualmente.

Faz-se necessário de olhar para este processo por uma perspectiva matizada 
e plural no qual a agricultura familiar constrói o seu potencial emancipatório a partir do emprego de seu trabalho e se seus conhecimentos na valorização do potencial ecológico, social e cultural local. Agricultura familiar encontra a sua autonomia se inserida na lógica de um território vivido e dotado de sentido.

Neste ponto se faz necessário retomar as reflexões de Santos sobre o regime de dominação atual da globalização hegemônica. Neste autor o sistema global mostra-se cada vez mais violento e imprevisível, aumentando a vulnerabilidade de regiões, nações e grupos sociais subordinados. Bauman (2005) problematiza o uso do termo globalização como o sinônimo de um destino irremediável, um processo irreversível e que afeta a todos na mesma medida. A ideia de globalização se pasteurizou e se uniformizou tanto como expressão de um sentido, quanto como forma de explicar processos e fenômenos sociais. Isto significa dizer que quanto mais experiências o termo pretende explicar, mais opacas e invisíveis se tornam estas experiências, reforçando a ideia de uma globalização no sentido único do termo.

O avanço da urbanização no território pesquisado se encontra dentro desta lógica global opaca na qual as configurações territoriais locais como as práticas agrícolas ativas e presentes na região se encontram encobertas. A globalização representa ao mesmo tempo a liberdade de determinados grupos sociais, e o destino indesejado e cruel para outros onde estes são vistos como localizados. Utilizando os referencias dicotômicos próprios da modernidade, ser local em um mundo global é sinônimo de privação e degradação social.

Como alternativa a esta lógica, Santos (2010) aponta para a necessidade do surgimento de economias de pequena escala na forma de contra-hegemonia em contraponto aos processos de globalização vigente. A única maneira de garantir a sustentabilidade é fazer uma transição para o local. Neste mesmo autor encontramos o conceito de terrenos de confrontação entre a globalização hegemônica e a globalização contra-hegemônica. O potencial emancipatório das lutas presentes nestes terrenos baseia-se em uma política de igualdade centrada na redistribuição social da riqueza e no reconhecimento das diferenças étnicas, culturais, raciais e sexuais.

Intensifica-se a necessidade de transformar estratégias de sobrevivência em 
fontes de inovação, de criatividade, se transgressão e de subversão. Ao refletirmos sobre a relação entre rural e urbano na cidade do Rio de Janeiro, pensamos sobre a resistência das práticas agrícolas neste território e estabelecemos mais que uma fronteira física, ou geográfica, uma fronteira epistemológica separando rural e urbano. Enquanto $\circ$ urbano se enquadra nas definições de globalização hegemônica, por oposição e consequência, o rural pode ser enxergado como a globalização contra-hegemônica. Neste ponto nos perguntamos quais as implicações identitárias desta condição fronteiriça na qual se encontram estes sujeitos.

\section{CONSIDERAÇÕES FINAIS: IDENTIDADES NA FRONTEIRA}

Partimos da concepção de que as identidades surgem a partir de processos históricos e sociais específicos e sua condição contextual é fruto de formas estruturais e de organizações sociais particulares (HALL, 1992). Para bem compreender de que forma se dá a dinâmica identitária entre os agricultores residentes no Maciço da Pedra Branca, é necessário analisá-la a partir do contexto específico de um território inserido em uma lógica de cidade onde se observa um processo de intensa urbanização e transformação social, fazendo com que as fronteiras entre o rural e o urbano estejam em constante transformação.

D'Ávila e Cavas (2014) conceituam a noção de fronteira a partir dos estudos pós-coloniais destacando a constante relação e interface com as noções de identidade, hibridismo cultural e diáspora. $\mathrm{O}$ processo de hibridação cultural, tão relacionado à globalização, dá à noção de fronteira, assim como às identidades, um estado de fluidez. Neste sentido a analise da relação rural-urbano-rural no Maciço da Pedra Branca ganha consistência teórica relevante. Podemos assim considerar que o território em questão se configura como uma fronteira fluida entre o rural e o urbano dentro da cidade do Rio de Janeiro, onde os mesmos não se encontram em oposição, mas sim em uma relação de continuidade. Subir e descer as trilhas que ligam a comunidade Astrogilda ao restante do Bairro da Vargem Grande é passar por um gradiente rural-urbano-rural onde as motos, os burros de carga, o asfalto, os caminhos de terra, os sítios, as casas novas e as pessoas se entrelaçam em uma 
ordem fluida. No caminho que trilhamos, a delimitação entre rural e urbano só pode ser percebida de longe, através de uma visão macro, que é própria de mapas tradicionais e a ideia de delimitação dá lugar a ideia de continuidade.

Ao aproximar a noção de fronteira do tema nas identidades, vemos que em Pratt (1992), assim como, em Ashcroft, Griffiths e Tifin (2000) a noção de fronteira se constitui como a delimitação dos territórios a partir de uma cartografia colonial. Esta presença da colonialidade expõe relações de dominação, onde o eu e o outro se encontram na diferença. Explicitando as relações de dominação próprias dos encontros coloniais, Pratt (1992) aproxima a idéia de fronteira da noção de zonas de contato onde as relações sociais são caracterizadas por assimetria.

Em cenários de instabilidade identitária, as pessoas estão constantemente cruzando fronteiras e transitando em busca de formas para a constituição de identidades culturais e sociais. Neste sentido as identidades não podem ser compreendidas somente em conexão com a produção de uma diferença ou oposição e sim como um processo social discursivo que busca a construção de algo inédito. Francisco define da seguinte forma os agricultores que vivem em sua comunidade: "As pessoas que vivem da agricultura são nascidas e criadas aqui. Ainda tem muito agricultor, mas eles são os heróis da resistência deste lugar."

Quando pensamos nos processos de urbanização, sempre somos levados a crer que este se dá pelo avanço da fronteira do urbano sobre o rural, e que nunca poderemos observar o caminho inverso. Partindo de uma leitura do espaço a partir dos discursos dos atores sociais que se encontram nesta fronteira o avanço das áreas urbanas sobre as rurais é entendido como a reconfiguração de uma fronteira, mas não pode significar o fim das constituições identitárias e sim um processo de reconfiguração das mesmas. De não-existentes estes agricultores passam a resistentes.

Observando outra fala de Jorge, observamos o componente da permanência no orgulho que sente pelo seu trabalho e por sua condição de agricultor: "Eu sou muito honrado de ser agricultor. Principalmente porque eu tenho conhecimento, hoje em dia, que em forneço alimento para as pessoas."

As dinâmicas identitárias, segundo Santos (2006) são suprimidas enquanto expressão de necessidade ou aspiração emancipatória pelos instrumentos 
hegemônicos de globalização. Estes mesmos instrumentos estão presentes nos processos galopantes de urbanização. A invisibilidade da agricultura e dos agricultores residentes no Maciço da Pedra Branca se dá por uma visão monocultural do Poder Público e das sociedades, eclipsada por uma junção das cinco lógicas de produção da não-existência expostas pelo autor.

No entanto a segunda fala de Jorge nos aponta o sentido positivo de uma identidade de agricultor, que reside na importância social do trabalho onde a produção de alimentos é o fator de afirmação de sua existência. É interessante observar que, ao afirmar que esta valorização é algo recente, Jorge nos revela um processo crescente de valorização da sua prática, da sua cultura e por conseqüência da sua identidade.

A constante tensão entre a invisibilidade e a valorização destas práticas se faz presente em todos os momentos de reflexão com os interlocutores da pesquisa. Enquanto Francisco e Jorge refletem sobre sua realidade de forma crítica onde as dificuldades, limites e fronteiras são destacados nos seus discursos, Sandro, produz a sua fala acentuando as potencialidades da luta da comunidade, mais do que os fatores limitantes. Compreendemos assim, que a dimensão ecológica e socioambiental também são caminhos de consolidação deste diálogo, bem como, um forte componente na dinâmica identitária deste agricultor familiar. Nesta relação, a terra não é apenas meio de produção, mas meio de propagação de um modo de vida cuja existência e legitimidade estão vinculadas a própria afirmação identitária. Estes elementos representam, entre outras coisas, a produção e a reprodução do conhecimento e dão corpo ao processo de constituição das identidades psicossociais destes sujeitos.

Ainda no processo de desvendamento das dinâmicas identitárias entre agricultores na cidade do Rio de Janeiro podemos apontar para a necessidade do abandono da dicotomía rural-urbano. Para isso é necessária uma perspectiva de renovação e reinvenção de paradigmas, porque o fazer científico esteve muitas vezes relacionado ao exercício de dominação que separou mais do que reuniu, que segregou mais do que incluiu, que alimentou referenciais epistemológicos de total separação. Neste sentido o fazer científico compromete-se com cientificismos, etnocentrismos e outros ismos que geram abismos entre visões de mundo e modos 
de existência diferentes. Agir no mundo rural pode ser hoje a oportunidade para acionar a reinstalação do dado sensível, recuperando autonomia e qualidade dos lugares a partir de suas singularidades, para resistir ao projeto de total unificação da lógica da globalização. 


\title{
IDENTITY DYNAMICS IN RURAL-URBAN-RURAL: TERRITORY AND BORDER AMONG FARMERS IN RIO DE JANEIRO
}

\begin{abstract}
:
The municipality of Rio de Janeiro is considered eminently urban, since this is the condition of $100 \%$ of its population. However, the reality we observe pierces the official census data, and the family agriculture remains active in some communities. This study takes place in the psychosocial field from an interdisciplinary perspective and analyzes the dynamics of identity between farmers in the city of Rio de Janeiro, from the notions of border and identities of postcolonial theory. We focus on a community that features century-old stories of practices related to agriculture, which show strong collective awareness of its social role: it claim its stay in place as a Forest region preservation factor and attributes its work due the importance of their social relations. In this way, we will approach the topic from the theoretical perspectives of sociology of absences and ecology of knowledge, as presented by Boaventura de Sousa Santos.
\end{abstract}

Keywords: Interdisciplinarity. Communities. Identities. Border. Post-Colonialism.

\section{DINÁMICAS DE IDENTIDAD EN EL MEDIO RURAL-URBANO-RURAL: TERRITORIO Y FRONTERA ENTRE AGRICULTORES DE RIO DE JANEIRO}

\section{Resumen:}

El municipio de Río de Janeiro es considerado eminentemente urbano, ya que ésta es la condición del $100 \%$ de su población. Sin embargo, la realidad que observamos va más allá de los datos oficiales del censo, y la agricultura de carácter familiar sigue siendo activa en algunas comunidades. Este estudio se lleva a cabo en el campo psicosocial desde una perspectiva interdisciplinaria y analiza la dinámica de identidad entre los agricultores en la ciudad de Río de Janeiro a partir de las nociones de frontera e identidad próprias de la teoría poscolonial. Nos enfocamos en una comunidad que cuenta com historias centenarias de prácticas relacionadas con la agricultura, que muestran una fuerte conciencia colectiva de su papel social: afirman su permanencia en el lugar como como factor de preservación de la selva de la región y atribuyen a su labor la debida importancia en sus relaciones sociales. En este sentido vamos a abordar el tema desde las perspectivas teóricas de la sociología de las ausencias y ecología de saberes como propone Boaventura de Sousa Santos.

Palabras-clave: Interdisciplinariedad. Comunidades. Identidades. Frontera. Poscolonialidad. 


\section{REFERÊNCIAS}

ASHCROFT, Bill. GRIFFITHS, Gareth. TIFIN, Helen(2000). Post-Colonial Studies. The Key Concepts. 2 ed.

BAUMANN, Zygmunt.(2005), Identidade. Rio de Janeiro: Jorge Zahar.

D'AVILA NETO, Inácia, CAVAS, Claudio. (2014). Frontières: Pour une nouvelle èpistémilogie de la notion. Vocabulaire des mobilités Culturelles, Bernd e Dei (org).

HALL, Stuart. (1992) A identidade cultural na pós-modernidade, Rio de Janeiro: DP\&A.

LEFEVBRE, H. (1999) A cidade do capital. Rio de Janeiro, RJ: DP\&A.

MARTÍN-BARBERO, Jesús. (2002). Ofício de Cartógrafo. Travessias latinoamericanas da comunicação na cultura, São Paulo: Edições Loyola.

MARTINS, José S. (2000). O futuro da sociologia rural e suas contribuições para a qualidade da vida rural. Revista Estudos Sociedade Agricultura. N 15. CPDA UFRRJ. Rio de Janeiro.

PETERSEN, Paulo. Agricultura familiar camponesa na construção do futuro, Rio de Janeiro, AS-PTA, 2009.

PLOEG, Jean. D. Dez Qualidades da Agricultura Familiar. Revista Agriculturas, Cadernos para debate, Rio de Janeiro, AS-PTA, 2014.

Sete Teses sobre a Agricultura Camponesa. In:

PETERSEN, Paulo. (org) Agricultura familiar camponesa na construção do futuro, Rio de Janeiro, AS-PTA, 2009.

PRATT, Mary Louise. (1992). Ojos Imperiales. Literatura de viajes y transculturación. Buenos Aires: Universidad Nacional de Quilmes.

SANTOS, Boaventura de Sousa. (2010). A gramática do Tempo: para uma nova cultura política. São Paulo: Cortez.

R. Inter. Interdisc. INTERthesis, Florianópolis, v.12, n.2, p.180-199, Jul-Dez. 2015 
SILVA, Tomaz Tadeu (org) (2000). Identidade e Diferença: A Perspectiva dos Estudos Culturais. Petrópolis: Vozes.

SILVA, C. ROCHA, F. (2011) Contribuição da Sociologia Rural Norte-americana e européia aos conceitos de rural, urbano e suas relações. Revista Colombiana de geografia. Vol. 20. Bogotá.

Artigo

Recebido em 30 de janeiro de 2015

Aceito em 05 de outubro de 2015 